\title{
BLOCKCHAIN E DEMOCRACIA: A NOVA TECNOLOGIA A SERVIÇO DA
} CIDADANIA

\author{
Igor Barbosa Beserra Gonçalves Maciel ${ }^{1}$
}

\section{RESUMO:}

O presente artigo versa sobre a relação da tecnologia blockchain com a democracia, a fim de saber se aquela pode servir para concretização da cidadania. Através do método de abordagem hipotético-dedutivo, de procedimental explicativo e da técnica de pesquisa bibliográficadocumental, objetiva-se: primeiramente, conhecer o blockchain. Em seguida, analisar a democracia com foco na publicidade dos atos estatais. Posteriormente, discorrer como a referida inovação tecnológica pode contribuir para a efetivação da cidadania. Por fim, apresentar as considerações finais sobre a presente temática.

PALAVRAS-CHAVES: blockchain. Democracia. Publicidade. Nova tecnologia. Cidadania.

\section{BLOCKCHAIN AND DEMOCRACY: THE NEW TECHNOLOGY AT THE SERVICE OF CITIZENSHIP}

\begin{abstract}
:
This paper deals the relationship of blockchain technology with democracy, in order to know if it can serve to realize citizenship. Through the hypothetical-deductive approach method, explanatory procedure and bibliographic-documentary research technique, the objectives are: firstly, to know the blockchain. Then analyze the democracy with a focus on publicizing state acts. Subsequently, discuss how this technological innovation can contribute to the realization of citizenship. Finally, present the final considerations on the present theme.
\end{abstract}

KEYWORDS: blockchain. Democracy. Publicity. New technology. Citizenship.

\section{INTRODUÇÃO}

A tecnologia computacional tem possibilitado inúmeras inovações, principalmente, após a década de 1990, período em que a internet ganhou ainda mais proeminência. Como consequência da constante evolução, em 2008, Satoshi Nakamoto apresenta ao Mundo a criptomoeda bitcoin, ao publicar o paper "Bitcoin: A Peer-to-Peer Eletronic Cash System”.

O Bitcoin trata-se de uma moeda digital que, muito embora não tenha explicitado em seu trabalho o termo blockchain, trouxe em seu cerne toda a ideia de funcionamento, ao

\footnotetext{
${ }^{1}$ Mestrando em Direito Econômico pelo Programa de Pós-Graduação em Ciências Jurídicas/UFPB. Bolsista CAPES/DEMANDA SOCIAL. Advogado licenciado. Editor Assistente da Prim@ Facie (Revista do PPGCJ/UFPB).
} 
asseverar que os registros das transações seriam feitos em blocos encadeados, após um rigoroso processo de validação, tendo como base a criptografia, para em seguida ser distribuído em toda a rede, aumentando a segurança contra fraudes do tipo "gasto duplo".

O blockchain pode ter diversas utilidades, como ser um bloco de notas, espaço negocial e autenticador de registros, a depender do que se almeja fazer, entretanto, em todas elas sempre haverá a anotações das informações de maneira permanente e a sua descentralização (distribuição), uma vez que as transações são publicizadas e cópias são enviadas aos integrantes do respectivo bloco.

Noutro giro, destaca-se que a Constituição da República Federativa do Brasil de 1988 (CRFB/88) adotou o Estado Democrático de Direito como forma de governo, atribuindo ao povo a titularidade do poder. Todavia, para além de mero discurso, é preciso viabilizar o exercício democrático por parte dos cidadãos.

Nesse sentido, são valiosas as considerações de parte da doutrina quanto à relação da democracia e da publicização dos atos estatais com a cidadania, uma vez que, conhecendo o Estado o cidadão poderá criticá-lo e, assim, buscar reformá-lo, ou legitimá-lo, na forma constitucional.

Entrementes, pode a tecnologia blockchain servir à efetivação da cidadania? Dentro desse novo contexto computacional é possível considerar que a inovação alhures pode ser um instrumento para a efetivação da cidadania, já que com o registro e a publicidade das informações do Estado o cidadão o conhecerá e, por conseguinte, estará apto a fazer juízo de valor, seja positivo ou seja negativo.

Assim, em linhas gerais, objetiva-se apresentar a tecnologia blockchain, fazer alguns apontamentos sobre a democracia e a publicidade dos atos estatais e, ainda, discorrer como a nova tecnologia pode ser útil para a concretização da cidadania, para, então, trazer as considerações finais.

A utilização da tecnologia em prol da democracia tem sido objeto de intensos debates pelos mais diversos ramos do saber, dentre eles, o da ciência jurídica, não só no Brasil, mas ao redor do Mundo. Isso pelo fato de a revolução digital estar proporcionando o surgimento de novas ferramentas, como a blockchain, que pode ser útil aos Estados e aos cidadãos, sobretudo, para a efetivação de direitos fundamentais, como é o caso da cidadania. 
A metodologia de abordagem utilizada para este estudo será a dedutiva. No tocante ao procedimento, o método empregado será o explicativo, como técnica de pesquisa, a bibliográfico-documental, a fim de estudar os posicionamentos doutrinários inerentes ao tema.

\section{BLOCKCHAIN: a tecnologia disruptiva}

O surgimento da internet é remoto à 1960, período em que o Mundo vivenciava a Guerra Fria entre os Estados Unidos da América (EUA) e a União das Repúblicas Socialistas Soviéticas (URSS). À época, as referidas Nações disputavam o poder e a hegemonia mundial, tanto no âmbito bélico como no âmbito tecnológico.

Dentro deste contexto, militares dos EUA desenvolveram o projeto Advanced Research Projects Agency (ARPA) ${ }^{2}$, cujo objetivo era a criação de um sistema de informações e de comunicação em rede que protegesse o Estado Americano de surpresas indesejáveis e de maiores prejuízos em caso de guerra nuclear. Tal projeto culminou com a aparição dos primeiros sinais de internet, denominado Arpanet (GILES, 2010).

Contudo, a internet como a qual conhecemos hoje só ganhou maior destaque e utilidade após os anos de 1990, isto é, quase trinta anos após os primeiros sinais, com o desenvolvimento do World Wide Web, pelo cientista e professor do Massachusetts Institute University (MIT) Timothy John Berners-Lee (BERNERS-LEE, 1992).

Com o surgimento da web, pessoas de todas as Nações começaram a se comunicar sem precisar sair de casa, além disso, fazer pesquisas dos mais diversos conteúdos, que passaram a ser lançados diretamente na internet, não se resumindo ao meio físico (livro ou CDs - tipo Barsa Enciclopédicas), até então, a única modalidade de compartilhamento de quaisquer espécies de informações.

O surgimento de novas formas de se relacionar, de compartilhar informações e de fazer negócios ao redor de todo o Mundo está sendo viabilizado pelo desenvolvimento constante da web, que também tem conferido cada vez mais celeridade e mais eficiências aos processos e ferramentas já existentes. Pode-se dizer que, hodiernamente, estamos vivendo uma grande revolução da informação, cujas consequências são gigantescas.

\footnotetext{
${ }^{2}$ Tradução livre: Agência de Projetos de Pesquisa Avançada.
} 
Em 1988, Harold F. Skip Weitzen já traçava ideias que seriam o prenúncio da atualidade e dizia que saber onde achar as informações, como também apresentá-las e utilizálas teria igual destaque que conhecê-las (ELIAS, 2003).

Nesse compasso, como fruto da evolução tecnológica computacional, em 2008, ocorre a apresentação do trabalho "Bitcon: A Peer-to-peer Electronic Cash System", de Satoshi Nakamoto, em que trouxe à tona a criptomoeda bitcoin, totalmente descentralizada (distribuída) e livre de qualquer ação estatal ou de terceiros intermediários.

O bitcoin tem como entre outras funcionalidades evitar os "gastos duplos", que são uma espécie de fraude ao credor, diminuir os custos transacionais, dar maior celeridade aos processos, bem como registrar tudo e compartilhar as informações, de modo que seja possível aumentar a segurança daqueles que o utilizam.

Entrementes, frisa-se que, em nenhum momento, o criador da nova tecnologia disruptiva de registro de dados menciona o termo blockchain em seu trabalho, não obstante descrever detalhadamente como seria o seu funcionamento, conforme se observa in verbis:

The steps to run the network are as follows:

1) New transactions are broadcast to all nodes.

2) Each node collects new transactions into a block.

3) Each node works on finding a difficult proof-of-work for its block.

4) When a node finds a proof-of-work, it broadcasts the block to all nodes.

5) Nodes accept the block only if all transactions in it are valid and not already spent.

6) Nodes express their acceptance of the block by working on creating the next block in the chain, using the hash of the accepted block as the previous hash (NAKAMOTO, 2008, p. 3) ${ }^{3}$.

Com o esmiuçar do processo por trás do bitcoin, claramente, constata-se o que, pouco tempo depois, ficaria conhecido como blockchain propriamente dito, isto é, a inovação tecnológica em que se registra todas as informações negociadas, fornecidas, anotadas, de ponto a ponto, após um processo matemático de validação, que a torna inviolável.

Que de fato é a tecnologia blockchain? ${ }^{4}$

\footnotetext{
${ }^{3}$ Tradução livre: As etapas para executar a rede são as seguintes:

1) Novas transações são transmitidas para todos os nós.

2) Cada nó coleta novas transações em um bloco.

3) Cada nó trabalha para encontrar uma prova de trabalho difícil para o seu bloco.

4) Quando um nó encontra uma prova de trabalho, ele transmite o bloco para todos os nós.

5) Os nós aceitam o bloco somente se todas as transações nele forem válidas e ainda não tiverem sido gastas.

6) Os nós expressam sua aceitação do bloco trabalhando na criação do próximo bloco na cadeia, usando o hash do bloco aceito como o hash anterior.
} 
Asseverando sobre a temática, Campos (2018) aponta:

[...] Blockchain é o banco de dados distribuído onde são processadas e registradas, de forma permanente, as operações realizadas em bitcoins. [...] O objetivo do Blockchain é ser uma prova permanente de todas as transações e prevenir o chamado 'gasto duplo' [...] todos os membros da rede possuem uma cópia do Blockchain em seu computador, qualquer transação inválida será evidenciada para todos [...] (CAMPOS, 2018, p. 37).

A prova permanente das transações é uma das características virtuosas proporcionadas pela inovação computacional, uma vez que com a distribuição do registrado para todos os integrantes, este servirá de prova e de parâmetro para a anotação de novas informações, consequentemente, impede a fraude contra credores, por exemplo.

Para Mougayar (2017), o blockchain pode ser banco de dados, uma rede de negócios, validador de transações, sem a presença de intermediários:

Tecnicamente, o blockchain é um banco de dados de back-end que mantém um registro distribuído que pode ser inspecionado abertamente.

Em modelos de negócio, o blockchain é uma rede de troca para movimento de transações, valores, ativos entre pares, sem a assistência de intermediários.

Legalmente falando, o blockchain valida as transações, substituindo entidades anteriormente confiáveis (MOUGAYAR, 2017, p.4).

Outra qualidade da tecnologia em apreço é a sua multiutilidade, como destacado alhures. Ainda sobre blockchain, segundo a Organização Não-Governamental ARTICLE 19, pode-se melhor conceituá-lo como:

[...] they are best conceptualised as a secure method of storing information due to their special qualities by design. Blockchains are ledgers with several copies in existence at the same time; if one copy is taken down or tampered with, the other copies will still exist. Data in the ledger is stored in a chronological sequence, or 'chain.' Each individual data container in the chain is called a 'block,' from which the term 'blockchain' derives. The blocks in a blockchain are interconnected by cryptography to ensure their validity. Blockchains can be both private and public, and both are examined as part of this analysis (ARTICLE 19, 2019, p. 9) . $^{5}$

\footnotetext{
${ }^{4}$ Antes de responder a presente indagação, pontua-se que o presente trabalho não pretender esgotar o assunto, além do mais, ao passo que é algo novo, é importante destacar que ainda não se tem por sedimentado o seu conceito. Desse modo, apresentar-se-ão as noções julgadas mais interessantes para esta pesquisa.

${ }^{5}$ Tradução livre: eles são melhor conceituados como um método seguro de armazenar informações devido a suas qualidades especiais pelo design. As blockchains são livros-razão com várias cópias ao mesmo tempo; se uma cópia for removida ou adulterada, as outras cópias ainda existirão. Os dados no livro-razão são armazenados em uma sequência cronológica, ou "cadeia". Cada recipiente de dados individual na cadeia é chamado de "bloco", do qual deriva o termo "blockchain". Os blocos de uma blockchain são interconectados por criptografia para garantir sua validade. Os blockchains podem ser privados e públicos, e ambos são examinados como parte dessa análise.
} 
Mais uma vez, observa-se que a segurança contida na nova tecnologia é um dos destaques, pois atribui alta confiança aos participantes do bloco, os quais sozinhos armazenam, garantem e validam os dados anotados, sem a necessidade de terceiros intermediários ou de um Estado Nação mantenedor.

Em inteligência aos conceitos e às definições apresentadas, afirma-se que o blockchain é marcado pela fungibilidade, tendo em vista que pode ser banco de dados, plataforma de desenvolvimento e viabilizador de rede.

Quanto à primeira, afirma-se que aquele funciona como uma espécie de livro contábil, em que é possível anotar de modo permanente as transações realizadas, além de permitir conhecer todo o histórico das negociações ocorridas no bloco de ponto a ponto, entre nós. Para a segunda, isto é, como uma plataforma de desenvolvimento, servindo de espaço para as negociações e para a movimentação dos negócios. Já para a última, a nova tecnologia presta-se à autenticação do informado de maneira independente.

Frisa-se que independente de qual característica seja predominante no blockchain, todas terão em seu cerne a anotação e o compartilhamento de dados, por conseguinte, "é capaz de garantir às pessoas mais controle, autonomia e privacidade" (CAMPOS, 2018, p.43).

Entrementes, como é o funcionamento da referida tecnologia disruptiva? ${ }^{6}$

Primeiramente, ressalta-se que o registro das informações é realizado e provado por meio de cálculos matemáticos, a fim de verificar a autenticidade, para a partir daí haver a distribuição do conteúdo para toda a rede, entre todos os nós.

A anotação no blockchain é segura, confiável, contínua, imutável, possuindo data e hora de registro. A confiabilidade das transações ocorre pelo fato de utilizar o sistema de criptografia, que é tão longínquo como a escrita, e evita adulteração. Nesse mote, arrazoam Marcacini e Costa (2003):

A criptográfica é tão antiga quanto a própria escrita, não é uma 'tecnologia' que surgiu com a informática, [...]. Teve, a criptografia, ao longo da História, aplicação praticamente exclusiva à esfera militar [...]. Na sociedade da informação, a criptografia tem demonstrado imprescindível utilidade para proteção da transmissão e armazenamento de informações [...]. Registros eletrônicos são facilmente alteráveis, daí a dificuldade inicial em aceitá-los como prova documental. A única maneira de evita que sejam adulterados é criptografá-los (MARCACINI; COSTA, 2003, p. 66-67).

\footnotetext{
${ }^{6}$ As explicações fornecidas no tocante ao conceito do blockchain também contribuem para a descrição de seu funcionamento. Aqui, pois será evidenciado o que é interessante à seara jurídica, notadamente, ao registro das informações, já que se pretende relacionar a inovação com a democracia e com a cidadania.
} 
Ainda sobre a criptografia, notadamente, a assimétrica cuja chave pública só pode ser decriptada com a chave privada equivalente e vice-versa, evidencia-se que esta é a utilizada na tecnologia blockchain, igualmente a da assinatura digital, possibilitando a garantia de procedência, o que reforça a confiabilidade.

Chaves assimétricas com 2.048 bits são consideradas suficientemente seguras (DEVEGILI; SANTOS, 2003). Quanto maior a chave, mais segura é. Isso porque torna praticamente impossível a reversibilidade, primeiramente, pelo fato de não existir tecnologia para isso, segundo, ainda que já fosse possível, o elevadíssimo custo financeiro juntamente com o longo tempo para fazê-la, que poderia ser de dezenas e até centenas de anos, seria desestimulador ou até mesmo um impeditivo.

No que diz respeito às redes, ressalta-se que não há um grande banco de dados contento todas as informações, mas blocos específicos, por exemplo, existe o blockchain de bitcoin, de entherum, de ripple, de bitcoincash, entre outros.

Desse modo, outras blockchains podem ser criadas para atender a interesses pontuais e, assim, constar as informações de quem realizou, para onde foi, quando ocorreu, a que horas se deu e, portanto, restringir desvios ao longo do caminho quando do registro das compras, dos pagamentos, de gasto com pessoal, seja no âmbito das empresas ou do Estado.

Também merece informar que a referida inovação precisa da internet para funcionar, contudo, pode operar por cima da web, através de uma versão mais descentralizada (Mougayar, 2017).

Quanto à descentralização, é salutar indicar como esta se comporta no blockchain. Eis as formas dos modelos de rede de compartilhamento:

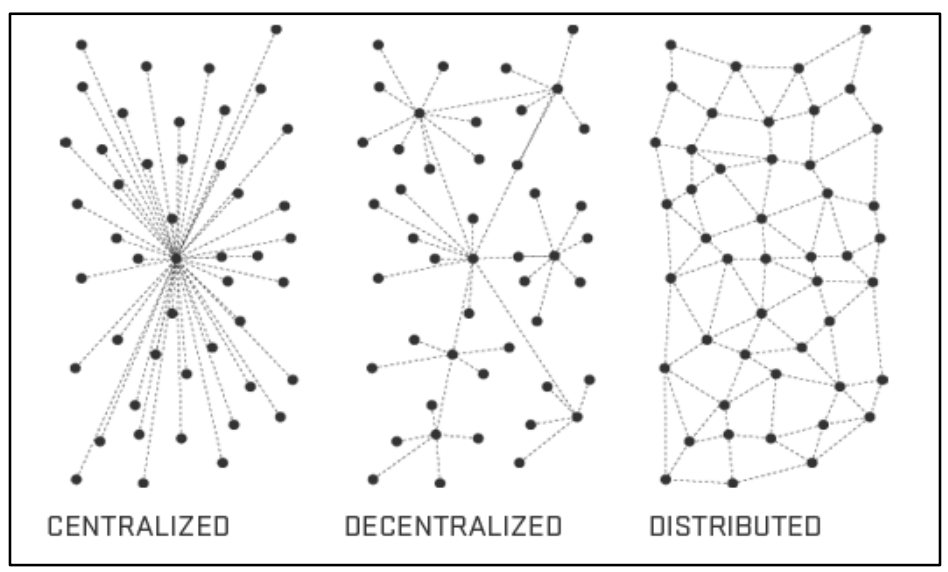


Figura1- Redes: centraliza, descentralizada (multicentralizada) e distribuída (descentralizada propriamente dita) ${ }^{7}$.

Diferentemente de uma rede centralizada, em que é possível visualizar apenas um centro de controle e de poder ligando todos os participantes, ou de uma rede descentralizada tipo multicentralizada, isto é, em que há vários centros de poder porém os integrante continuam desconectados, no formato da blockchain inexiste centro de controle e de poder, o que o uma rede distribuída ou descentralizada propriamente dita ${ }^{8}$, pois os participantes estão conectados em si, de modo que cada um possui a cópia de todas as informações transmitidas.

A distribuição acaba por reforçar a segurança das informações, pois, caso a rede eventualmente seja atacada e, por consequente, um nó ou vários nós sejam destruídos, basta apenas sobrar um para que se restaure o bloco, tendo em vista que este terá uma cópia dos registros ocorridos no blockchain.

Em suma, observa-se que a nova tecnologia almeja possibilitar e facilitar o registro de todas a operações realizadas, anotando-as em um bloco dentro da grande rede mundial de computadores, isto é, da web, sem a necessidade de um terceiro intermediário e de modo distribuído, uma vez que os registros são compartilhados entre os integrantes da rede. Ainda, a autenticação se dar por meio de criptografia, que confere a tecnologia um alto grau de segurança e de confiabilidade, pois o que destoar dos registros será invalidado.

Com efeito, o blockchain é considerado uma tecnologia disruptiva pois, ao descentralizar (distribuir) as informações, trouxe-se consigo uma quebra de paradigma em relação ao modelo registral, negocial e informacional até pouco tempo existente.

Diante disso, será evidenciado no presente trabalho a anotação de informações no blockchain, tendo em vista a possibilidade de se relacionar com a democracia e servir ao exercício da cidadania, consoante se analisará a seguir.

\section{DEMOCRACIA E A PUBLICIDADE DOS ATOS ESTATAIS}

No Estado Brasileiro, a opção política de governo foi a democrática, a qual se encontra enraizada no art. $1^{\circ}$, caput e parágrafo único, da CRFB/88, que assim preconiza:

\footnotetext{
7 Figura 1 - Redes: centraliza, descentralizada (multicentralizada) e distribuída. Disponível em: <https://images.app.goo.gl/zMehhP22HPMH3K5w7>. Acesso em: 20 ago. 2018.

${ }^{8}$ No presente trabalho, quando se referir ao blockchain como rede uma descentraliza estar-se-á a considerá-la como uma rede distribuída e não multidescentralizada.
} 
Art. $1^{\circ}$ A República Federativa do Brasil, formada pela união indissolúvel dos Estados e Municípios e do Distrito Federal, constitui-se em Estado Democrático de Direito e tem como fundamentos. [...] Parágrafo único. Todo o poder emana do povo, que o exerce por meio de representantes eleitos ou diretamente, nos termos desta Constituição (BRASIL, 2019).

A despeito do assentando no Texto Maior brasileiro, falar de democracia é mais do que se referir à governo do povo, que é o titular do poder, como depreendido da palavra grega demokratia, em que demos é povo, e kratos é governo, ou do conceito apresentado por Hobbes (2002, p.119): “quando o poder reside num conselho, no qual todo cidadão tem direito de votar, é chamado democracia. [...] quem governa é chamado demos, o povo."

A história demonstra que o ideal democrático foi além da significação grega e da visão hobbesiana, cujas características eram um liberalismo autoritário, em que o poder era centrado na figura do Soberano, superando-as. Conduto, a evolução da concepção democrática não foi constante e gradual até chegar à concretização do princípio republicano, para o qual a liberdade deve ser assegurada pela lei e pelo governo constitucional. Muito se percorreu, de modo que é importante fazer, ainda que bem resumidamente, uma contextualização.

Pois bem, não obstante à democracia ter raízes na Grécia antiga, o exercício democrático, à época, foi muito diferente do hodierno, pois era autocrático. Em Roma, o poder foi exercido pela aristocracia e a plebe também conseguiu alguns direitos, inclusive, em certa medida, o exercício da cidadania, inclusive para estrangeiros. Todavia, muitos cidadãos romanos foram excluídos, já que os direitos cidadãos se restringiram a capital do Império Romano, qual seja, Roma (SOUZA; SPAREMBERGER, 2018).

$\mathrm{Na}$ idade média, há quase o desaparecimento da democracia, sendo encontrado alguma expressão de governo popular apenas no Norte da Itália. Durante a antiguidade, o homem só era compreendido plenamente quando membro da polis. No tempo moderno, ocorre a volta do pensamento democrático, passando à compreensão do indivíduo e da sociedade como um conjunto deste (Idem, Ibidem).

Até a chegada do modelo atual de democracia, em que na maioria das Nações há participação popular, direito e igualdade ao sufrágio, esclarecimento, certo grau de publicidade dos atos estatais, observa-se, sobretudo, que sempre se lutou por liberdade.

Nesse sentido, a liberdade deve ser entendida como o princípio basilar da humanidade, tendo em vista que através dela os cidadãos podem expressar suas vontades, 
para, então, decidir a vida privada, como também para a formação de um Estado, cujos interesses e características reflitam o tipo de sociedade que o fundamente.

Por sua vez, vem a calhar os ensinamentos de Kelsen (1990), os quais afirmam que a liberdade se comporta como o núcleo da democracia e, juntamente com a igualdade, impõe que cada um seja livre e seja igualmente considerado, para participar da formação da vontade geral.

No tocante à participação do povo, dos cidadãos, no modelo democrático de Estado, Martins (2004) discorre que a transparência do poder e o compromisso social são fundamentais:

[...] Sabe-se que existem as mais variadas definições deste tema, sendo que nenhuma delas pode deixar de incluir como elementos fundamentais a questão da transparência do poder e a necessidade de uma estratégia de compromisso entre as partes através do debate permanente, respeitando-se as diferenças [...] (MARTINS, 2004, p. 230).

Com efeito, não obstante inexistir uma forma única de democracia, devem estar presentes na construção da sociedade a transparência do poder e o compromisso social, os quais conduzirão ao respeito às diferenças de opinião, de escolhas, de preferência por uma ou outra proposta política estatal.

Entretanto, a atribuição do direito de participar direta ou indiretamente a determinado número de cidadãos, bem como a existência de regra da maioria não são suficientes para democracia. Faz-se necessário que seja garantido os direitos de liberdade, de opinião, de expressão, aos chamados para decidir (BOBBIO, 2000).

Mais do que uma declaração de titularidade ou de atribuir àqueles a origem da soberania, faz-se necessário possibilitar o seu exercício pelo povo, pelos cidadãos, em compasso com os governantes. A execução deve ser atual e viabilizar à capacidade dos cidadãos de construírem a opção política apartada dos governantes (MIRANDA, 2013).

Nesse compasso, a publicidade dos atos estatais pode ser um importante instrumento para viabilizar o exercício da liberdade, do poder e da participação do povo no governo em um Estado Democrático de Direito, a exemplo da República Federativa do Brasil.

A democracia tem como um dos seus pilares a publicidade, já que possibilita ao cidadão conhecer as ações estatais e, a partir daí, poder criticar pretensões secretas, voltadas para interesses privados, os quais não são admitidos legalmente, pois os atos do Estado deve ser voltar para o coletivo (KANT, 2006). 
Conhecer o Estado é salutar tanto para criticá-lo, a fim de obter a sua reformulação e, portanto, aprimorar as suas atividades, os seus serviços, as suas prestações, entre outras áreas, quanto para legitimá-lo, reconhecendo o poder, a soberania, os acertos, as opções políticas, como se infere do asseverado por Lima (2011):

Na verdade, o pensamento de Kant implica em síntese entre republicanismo e liberalismo sendo, portanto, a publicidade e a crítica pública ao Estado pelo cidadão vetores importantes de tais objetivos políticos a fim de cumprir com fito kantiano de reforma do Estado e, ao mesmo tempo, assegurar a autoridade política constitucionalmente constituída (LIMA, 2011, p.145).

Da leitura da "Paz Perpetua" de Kant, constata-se que uma das bases do republicanismo é a publicidade dos atos estatais. Ser republicano é ser legal, com isso, a legalidade também deve ser fundamentada na publicidade, para permitir nas relações privadas a regulação legal-constitucional. A publicidade afeta o âmbito externo, de modo que ao Estado é vedado a realização de acordos secretos (LIMA, 2011).

É se baseando na publicidade que Jeremy Bentham fundamenta o seu modelo constitucional, a publicidade dos atos estatais traz consigo a vigilância contra as distorções do poder, a prevalência do interesse pessoal sobre o coletivo (STIGLITZ, 2013).

A representação política enseja responsabilização, desse modo, o Estado deve prestar contas à sociedade, que o julgará. Nesse mote, Miranda (2013), apresenta:

A representação política implica a responsabilidade política, ou seja, o dever de prestar contas por partes dos governantes, a sujeição a um juízo de mérito sobre os seus actos e actividade por parte dos governados e a possibilidade de sua substituição por actos destes (MIRANDA, 2013, p. 265).

Lembra-se que somente pela lei é que se tem a essência do Estado republicano revelada (KANT, 2010). Ainda, o poder legislativo deve-se limitar à vontade do povo unida e não pode causar, pela lei, injustiças aos integrantes da sociedade. Em suma, os representantes não podem ser tirânicos ou agir ilegalmente (KANT, 2005).

O conjunto de responsabilidades que gira em torno do representante político impõe que este seja transparente, para constantemente ser lembrado de qual é o fim perseguido pelo Estado Democrático, que é a concretização dos interesses da coletividade. Ao representante não cabe a supressão do interesse público pelo privado, que pode ser o seu ou de outrem.

Destarte, afirma-se que a democracia e a publicidade estão imbricamente interligadas, tendo em vista que a relação dessas duas reverberam diretamente na cidadania, que também é fundamental para uma república. 
Quanto à cidadania, esta pode ser revelada de três modos, quais sejam, comunitária, liberal e republicana. Na comunitária, há uma interação do indivíduo com a comunidade política, através da atuação e da decisão. Em que pese ter pensando na asfixia da minoria sobre a maioria, é possível ver em Rousseau (2011) a cidadania da comunidade:

[...] em vez da pessoa individual de cada contratante, esse ato de associação produz um corpo moral e coletivo composto de tantos membros quanto votos tem a assembleia, o qual recebe desse mesmo ato sua unidade, seu eu comum, sua vida e sua vontade. Essa pessoa pública [...] toma agora o de República ou de corpo político [...]. Quanto aos associados, eles tomam coletivamente o nome de povo e se chamam em particular de Cidadãos, enquanto participes de uma autoridade soberana (ROUSSEAU, 2011, p.66$67)$.

O cidadão se desprende de si, para agir em prol de um interesse maior, de uma vida e de uma vontade geral, que é representada pela coletividade. O indivíduo é visto e compreendido como parte integrante da comunidade e nela encontra o referencial dos valores políticos do bem comum (LIMA, 2017).

$\mathrm{Na}$ seara liberal, tem-se os direitos individuais da pessoa humana, de caráter público, representam, em latu senso, a reação à ação estatal. O indivíduo é livre para atuar dentro de seus interesses, de sua individualidade, desde que não viole às leis.

Quanto ao aspecto republicano, vê-se a defesa do interesse coletivo, possibilitando que o cidadão tenha acesso às informações e participe, direta ou indiretamente, da tomada de decisões do Estado (IRIBURE JÚNIOR, 2013).

No tocante ao exercício da cidadania, conforme já mencionado, é preciso ir além do discurso, para viabilizar o pleno exercício da democracia e, por sua vez, concretizá-la. Discorrendo sobre a temática, Iribure Júnior (2013) diz:

Reconhecendo à cidadania o status de fundamento republicano, a Carta Política atual adverte que nas relações entre Estado e indivíduo, seja em que dimensão esta se travarem, haver-se-á de serem aplicados mecanismos que assegurem efeitos práticos para materializar estruturas mínimas que façam perceber o indivíduo como membro ativo e participante dos direitos fundamentais plasmados nos textos daquele documento régio do ordenamento jurídico nacional (IRIBURE JÚNIOR, 2013, p. 200, grifo nosso).

Destaca-se que um dos caminhos para percepção do cidadão como participante da construção social do Estado é o da divulgação dos atos estatais, pois, ao conhecer a república o cidadão estará qualificado para o exercício público da razão, intervindo no debate da condução daquele de maneira esclarecida e livre. 
A liberdade de pensar tem de ser encarada como um tesouro, uma ferramenta contra abusos. A razão também pode ser considerada um remédio contra os arbítrios gerados pelo Estado e seus representantes. Asseverando sobre o uso público da razão apresentada por Kant, Lima (2017) evidencia quão preciosa é a liberdade cognoscente:

Kant mostra o quão poderosa é a liberdade de pensar como antídoto ao arbítrio, a forma de uma liberdade de expressão construída jurídica e criticamente (uso racional-prático da faculdade de julgar) enquanto formação do processo de comunicação constitui uma resistência ao caráter compulsório de sociedades não publicizadoras do fundamento do poder que as rege - daí o princípio da publicidade ser tão caro a Kant (AA 08:386), de modo que a todos os atos do executivo sejam publicados, a fim de garantir o controle democrático dos mesmos (LIMA, 2017, p. 96).

Frisa-se que a cidadania não se reduz simplesmente ao poder de votar, esta deve ser compreendida como um conjunto de faculdades decorrentes do exercício da liberdade de expressão, que norteia uma república. Desse modo, a crítica ao Estado representa um contributo fundamental ao espírito de liberdade, que para Kant é irredutível.

Nesse compasso, tem-se que a publicidade dos atos estatais está diretamente ligada à democracia, à república, à cidadania, uma vez que através da razão humana vêm as críticas, bem como a legitimação do Estado Democrático de Direito. Com mais informações o público discernirá com mais convicção, precisão, as ações públicas (STIGLITZ, 2013).

Com efeito, o Estado deve dar transparência aos seus atos, atividades, decisões, entre outras, pois é preciso instrumentalizar os cidadãos com o saber, para que então a republica seja verdadeiramente vivenciada, construída, tendo como norte os interesses dos titulares do poder, que é o povo. Este sim, deve ter o controle do estatal, legitimando-o ou criticando-o, no último caso, buscando reformá-lo, sobremodo, para a consecução do fim coletivo.

Para Lima (2017), em sendo o povo o soberano, não lhe pode restringir a busca por direitos. Ao cidadão deve ser proporcionado a participação no processo construtivo do Estado. O uso público da razão, portanto, viabiliza uma liberdade racional, indicando a obediência da lei natural por qualquer homem. A crítica aos atos estatais transcende a estes, pois também direciona os parlamentares quando da construção da lei e da interpretação da Constituição.

Outrossim, é importante ressalta-se que a liberdade de crítica ao Estado não significa o fim da capacidade legislativa dos parlamentares, mas um complemento à república.

Acreditamos que essa liberdade crítica ao Estado faculta a autonomia do cidadão e ao mesmo tempo sua participação efetivadora na legislação, sem derrogar a capacidade legislativa do parlamento, mas a complementando em 
vista da republicanização constante (reformismo) do Estado (LIMA, 2017, p. 163).

Dessa maneira, voltando-se ao Estado Brasileiro, uma vez que é Democrático de Direito, pode-se afirmar que este não pode omitir os seus atos, pelo contrário, deve publicizálos ao máximo, a fim de viabilizar o uso público da razão pelo verdadeiro titular do poder, que é o povo, os seus cidadãos e, assim, ser-lhes permitido frear os abusos e os desvios de finalidade, os quais podem ser praticados pelo Estado e por seus representantes.

Ademais, a participação dos cidadãos na construção do Estado reforça o princípio republicano, tornando-o mais democrático, por sua vez, caminhar para efetivação de direitos fundamentais ao tempo em que se distancia de um governo tirano.

Assim, tem-se que não há democracia sem que seja possibilitado aos formadores do Estado o direito de conhecer as suas atividades, os seus atos e as suas intenções, pois é a partir daí que há a formação e o exercício de uma própria ratio decidendi. Ademais, deve o Estado Democrático de Direito promover à publicidade dos seus atos, o que pode ser feito de várias maneiras, inclusive, através da tecnologia, como discorrer-se-á a seguir.

\section{A NOVA TECNOLOGIA A SERVIÇO DA CIDADANIA}

Consoante argumentando no ponto anterior, o acesso à informação é de suma importância para a participação democrática e para a legitimação dos atos estatais. Aquele se apresenta como uma ferramenta para república, pois possibilita que o cidadão faça uso público de sua razão e, por conseguinte, através das críticas ao Estado contribua para a formação desse.

Nesse contexto, é preciso que o Estado viabilize meios para a divulgação dos seus atos, sobretudo, pelo fato de que a Carta Constitucional brasileira de 1988 atribuiu à cidadania natureza de direito fundamental, cabendo ao Estado promover aos cidadãos acesso à participação governamental, além de lhes proporcionar inúmeros direitos e garantias.

Esta postura se coaduna com o modelo de estado adotado, que foi o Estado Democrático de Direito, e é ratificada ao longo do Texto Maior, em que se encontra diversos dispositivos permitindo o acesso à informação ou determinando a publicização dos atos estatais, por exemplo, têm-se: inciso XIV, do art. $5^{\circ}$, que assegura a todos o acesso à informação, guardando-se o sigilo da fonte, se for necessária ao exercício profissional; o 
caput do art. 37, traz a publicidade como um dos princípio basilares da Administração Pública; o caput do art. 220, assegura a liberdade de pensamento e informação; entre outros.

Igualmente, vê-se tal preocupação na Lei de Introdução às Normas do Direito Brasileiro, quando atribui ao início da vigência normativa a publicidade oficial, bem como o transcurso de, em regra, quarenta e cinco dias. Além disso, determinar que os atos administrativos latu sensu sejam devidamente fundamentados e expressem as consequências jurídicas de seus efeitos.

Entrementes, tendo em vista que a publicidade dos atos estatais é cara para a democracia, pode a tecnologia do blockchain servir à cidadania?

Ressalta-se, inicialmente, que com o desenvolvimento da internet a interação social melhorou e ficou mais eficaz, como arrazoam Oliveira e Rodegheri (2014):

A transformação propiciada pela Internet decorre da caracterização como uma ferramenta multicanal que agrega vários tipos de mídia em um só ambiente, pois permite a coexistência de textos, imagens, sons e vídeos, facilitando a ocorrência de interações, de forma muito mais rápida e atingindo um público cada vez maior de pessoas localizadas em várias partes do mundo (OLIVEIRA; RODEGHERI, 2014, p. 201).

É dentro da referida evolução computacional que as novas tecnologias estão surgindo e/ou crescendo, a exemplo do compartilhamento de dados nas nuvens, dos serviços de streaming, das criptomoedas, destacadamente, o bitcoin, que foi a primeira moeda digital a surgir e trouxe em seu cerne a apresentação do blockchain, que como aduz Ivancsics (2019):

The most popular terms used by blockchain explanations are decentralized, immutable, transparent, distributed (ledger), and trustless networks. Most of these descriptions refer to the same basic idea: let there be a record of stuff (data) that people can agree on and not change in the future, and secure that stuff so that all its history is constantly visible to everyone. In the world of blockchain, trust and memory are built block by block (IVANCSICS, 2019) ${ }^{9}$.

O blockchain ganha notoriedade em razão da capacidade de registrar todas as informações das transações realizadas em bloco, permitindo-se saber quem é o autor, quando foi feito, a que horas ocorreu e visualizar toda a cadeia negocial. Ademais, o fato de as informações só serem assentadas após validadas, reforça a autenticidade, não dando margem

\footnotetext{
${ }^{9}$ Tradução livre: Os termos mais populares usados pelas explicações do blockchain são redes descentralizadas, imutáveis, transparentes, distribuídas (ledger) e mesmo interferência. A maioria dessas descrições se refere à mesma ideia básica: que haja um registro das coisas (dados) com as quais as pessoas possam concordar e não mudar no futuro, e assegurar essas coisas para que toda a sua história seja constantemente visível para todos. No mundo do blockchain, confiança e memória são construídas bloco por bloco.
} 
para fraude, uma vez que o "livro-razão" também é distribuído entre todos os participantes. Eventual incompatibilidade da informação atestará a sua invalidade e, assim, a sua rejeição.

Noutro giro, aponta-se que, no Brasil, já há algumas formas de participação democrática por meio da internet, como o Governo Eletrônico $(e G O V)$, que permite aos cidadãos o acesso à informação e o acompanhamento dos serviços do Estado.

As ações do programa de Governo Eletrônico (eGOV) priorizam o uso das tecnologias da informação e comunicação (TICs) para democratizar o acesso à informação, visando ampliar o debate e a participação popular na construção das políticas públicas, como também aprimorar a qualidade dos serviços e informações públicas prestadas.

A política de Governo Eletrônico do Estado brasileiro segue um conjunto de diretrizes baseado em três ideias fundamentais: participação cidadã; melhoria do gerenciamento interno do Estado; e integração com parceiros e fornecedores (BRASIL, 2019).

Com o referido programa, busca-se transformar a sociedade e viabilizar a interação com os cidadãos, a fim de otimizar os serviços públicos e dar maior eficiência à Administração Pública. Além desse instrumento, existem outros, como o Portal da Câmara dos Deputados, do Tribunal de Contas das União, dos Tribunais de Contas dos Estados.

Contudo, o blockchain acaba por se diferenciar dos demais meios on-line de participação democrática, tendo em vista que com a nova tecnologia é possível ir mais além, quando permite à distribuição do conhecimento de muito mais informações e de maneira imutável, com toda riqueza de detalhes pontuadas alhures.

Quanto às várias serventias do blockchain, Campos (2018) apresenta que este pode ser utilizado no âmbito eleitoral, administrativo, financeiro, entre outros:

Isso sem falar na possibilidade de implementar processos eleitorais, administração e prestação das contas públicas pelo Blockchain, de forma rastreável, imutável e transparente para os cidadãos. Trazendo acesso à informação e controle sobre seus dados, é possível fazer algo extremamente significativo em prol da humanidade: diminuir o tamanho do Estado, em prol do cidadão (CAMPOS, 2018, p. 44).

Valendo-se de todas as características do blockchain, é possível utilizá-lo para conhecer ponto a ponto o conteúdo e o percurso das atividades estatais. Por exemplo, saber quanto o Estado gastou para a feitura de uma ponte, de uma estrada, de um hospital, para compra de medicamentos, de alimentos, etc.

Nesse alamiré, em sendo o conhecimento das atividades estatais um dos elementos fundamentais para a promoção das críticas e da legitimação do poder, o uso da nova 
tecnologia para a divulgação daquelas acaba por contribui para a participação popular na construção deste.

Ainda, a publicidade dos afazeres do Estado através do sistema blockchain ao passo em que dá aos cidadãos o direito de conhecer quais são as reais intenções daquele que se diz representar a coletividade, também permite conhecer o paradeiro do dinheiro público detalhadamente e, em caso de desvio de finalidade pública, possibilita à Polícia, aos Ministérios Públicos e ao Poder Judiciário agir mais rapidamente para minimizar os danos ao erário.

Com efeito, ter-se-á uma sociedade civil instrumentalizada para tomar a decisão necessária quanto ao tipo de Estado que quer, pois poderá legitimá-lo ou clamar por reformálo. Outrossim, aos demais órgãos controladores e fiscalizadores do poder também será fornecido elementos para frear os desvios de finalidade.

Segundo Stiglitz (2013), em um Estado Democrático a transparência pública é um direito básico:

[...] há, em sociedades democráticas, um direito básico ao conhecimento: um direito à informação sobre as atividades do governo e às razões pelas quais o governo realiza estas atividades. Quero argumentar, de modo ousado, que deveria haver um pressuposto forte a favor da transparência e da abertura do governo (STIGLITZ, 2013, p. 48).

A transparência proporcionada pela publicidade das atividades do Estado não são um fim em si mesmo, mas uma forma de melhor conhecer o interior daquele. Ademais, o acesso à informação articula-se como os direitos humanos, pois é visto como uma ferramenta para a promoção dos direitos sociais, direito criminal, entre outros (ANGÉLICO, 2013).

Observa-se, portanto, que as novas tecnologias trazem um cenário otimista de participação política popular, aumentando, sobremodo, a capacidade dos cidadãos de agirem decisivamente na defesa dos interesses democráticos (OLIVEIRA; RODEGHERI, 2014).

Em reforço, salienta-se que nos últimos anos o acesso à informação tem sido decisivo para as democracias ao Mundo, no Brasil, não tem sido diferente. A obtenção de conteúdo verídico e autentico acaba por fortalecer à república, tanto do ponto de vista da tomada de decisões por parte dos cidadãos como do próprio Estado.

Os benefícios gerados pela transparência estatal através da nova tecnologia transcendem à participação democrática do cidadão comum, uma vez que a distribuição das 
informações será igualmente útil às demais esferas administrativas, aos Poderes Legislativos, Judiciário e aos órgãos de controle externo, Tribunais de Contas e Controladorias.

A este respeito, caso no Brasil já houvesse um sistema de registro das ações administrativas como o proposto pelo blockchain, seja no tocante às informações gerais ou, mais especificamente, à realização de pagamentos, seria possível rastrear a maior parte dos valores desviados como consequência da corrupção sistêmica que assola o Estado, uma vez que com o histórico do caminho percorrido pelo dinheiro público saber-se-ia nó a nó o seu destino.

Destarte, não há dúvidas que a tecnologia blockchain poderá servir à efetivação da cidadania, pois, através dos registros constantes, autênticos, imutáveis, descentralizados (distribuídos), ao cidadão será proporcionado o acompanhamento integral das atividades estatais, elevando o grau de fiscalização. Por sua vez, haverá elementos para o uso racional das faculdades, tanto para criticar o Estado como para legitimá-lo.

\section{CONSIDERAÇÕES FINAIS}

O desenvolvimento da internet e das tecnologias dela decorrentes, pensadas, elaboradas, como é a tecnologia blockchain, têm possibilitado novos caminhos às negociações, às interações e às comunicações, porém, a evolução também pode ser utilizada para o fortalecimento da democracia nos dias atuais.

No tocante à democracia, viu-se que é necessário mais do que legitimar o povo, é fundamental instrumentalizar a participação daqueles no poder. Nesse contexto, a publicidade dos atos estatais apresenta-se como um de seus pilares.

Com o acesso à informação, o cidadão possui elementos para a participação na construção do Estado e na tomada de decisões, as quais podem conduzir para legitimar o soberano ou até mesmo criticá-lo, clamando por reformas.

Dessa maneira, a nova tecnologia contida no blockchain pode ser uma importante ferramenta, uma vez que permite o registro seguro das informações, as quais, após um rigoroso processo de autenticação, são transmitidas para os demais integrantes da rede. Ademias, permite o conhecimento pormenorizado de todo o percurso da informação, seja ela qual for, além de ser permanente, o que evita a supressão de inverdades ou implantação de omissões. 
Ressalta-se que, no Brasil, já há algumas formas de participação democrática on-line, como o eGOV e os portais da transparência, principalmente, dos Tribunais de contas, todavia, diferem do blockchain, uma vez que nesta é possível publicitar as atividades do Estado de ponta a ponta. Por exemplo, permite-se conhecer o passo a passo das compras e dos gastos públicos com obras, de modo confiável, rápido e em cadeia ao cidadão.

O registro das informações no blockchain são sempre atualizados, imutáveis e verídicas, por conseguinte, caso o Estado utilize a referida inovação para a publicidade de seus atos, a participação da sociedade na gestão governamental será instrumentalizada e, certamente, contribuirá para o aumento da fiscalização dos atos estatais e do controle contra ilegalidades.

Caso ocorram desvios de finalidade, os quais acabam por quebrar o contrato social atualmente existente no Brasil, posto pela Magna Carta de 1988, haverá mais facilidade para identificar o problema, bem como contê-lo com mais celeridade e mais precisão.

Nesse sentido, pode-se afirmar que os benefícios gerados pela nova tecnologia contida no blockchain transcendem à participação democrática do cidadão comum, pois as informações registradas no bloco também serão úteis à todas esferas administrativas, como aos Poderes Legislativos, Judiciário e aos órgãos de controle externo, Tribunais de Contas e Controladorias.

Destarte, da relação entre o blockchain e a democracia, constata-se que o primeiro pode servir à concretização da cidadania, já que a divulgação das atividades estatais em sua rede fornecerá elementos para o uso racional das faculdades pelos cidadãos, os quais, por sua vez, são os titulares do poder e poderão fazer criticas ao Estado ou legitimá-lo.

\section{REFERÊNCIAS}

ANGÉLICO, Fabiano. Acesso à informação pública: valores, potencialidades e desafios. In: SANTI, Eurico Marcos Diniz de et al. (coordenação). Transparência fiscal e desenvolvimento: homenagem ao professor Isaias Coelho. 1 ed. São Paulo: FISCOSoft Editora, 2013.

ARTILCLE 19. Blockchain and freedom of expression. Disponível em: <https://www.article19.org/wp-content/uploads/2019/07/Blockchain-and-FOE-v4.pdf>. Acesso em: 09 ago. 2019.

BERNERS-LEE, T.J., et al. World-Wide Web:information universe, Electronic Publishing: Research, Applications and Policy, April 1992. Disponível em: < 
http://www.emeraldgrouppublishing.com/products/backfiles/pdf/backfiles_sample_5.pdf>. Acesso em: 11 ago. 2019.

BRASIL. Constituição da República Federativa do Brasil de 1988. Disponível em: < http://www.planalto.gov.br/ccivil_03/Constituicao/ConstituicaoCompilado.htm>. Acesso em: 10 ago. 2019.

BRASIL. Ministério da Economia. Governo Digital. Disponível em:

<https://www.governodigital.gov.br/EGD/historico-1/his>. Acesso em: 17 ago. 2019.

BOBBIO, Norberto. O futuro da democracia. 7. Ed. São Paulo: Paz e Terra, 2000.

CAMPOS, Emília Malgueiro. Criptomoedas e blockchain: o direito no mundo digital. Rio de Janeiro: Lumen Juris, 2018.

DEVEGILI, Augusto Jun; SANTOS, Aline Sueli de Salles. Conceitos de criptografia e sua relação com o direito. (Segurança e autenticidade). In: KAMINSKI, Omar (organizador). Internet legal: o direito na tecnologia da informação. Curitiba: Juruá, 2003.

ELIAS, Paulo Sá. O documento eletrônico, a criptografia e o direito. (Revolução digital). In: KAMINSKI, Omar (organizador). Internet legal: o direito na tecnologia da informação. Curitiba: Juruá, 2003.

GILES, David. Psychology of the media. New York: Palgrave Macmillian, 2010. HOBBES, Thomas. Do cidadão. Tradução, apresentação e notas Renato Janine Ribeiro. 3 ed. São Paulo: Martins Fontes, 2002.

IRIBURE JÚNIOR, Hamilton da Cunha. As dimensões de justiça e cidadania no sistema constitucional brasileiro. In: LEITE, George Salomão; SARLET, Ingo Wolfgang.

Constituição, política e cidadania. Porto Alegre: GIW Editora, 2013.

IVANCSICS, Bernat. Blockchain in Journalism. Publicado em 25 jan. 2019. Disponível em: <https://www.cjr.org/tow_center_reports/blockchain-in-journalism.php>. Acesso em: 16 ago. 2019.

KANT, I. A metafísica dos costumes. Princípios metafísicos da doutrina do Direito. Tradução José Lamego. Lisboa: Fundação Calouste Gulbenkian, 2005.

Teoria y prática. Em torno al tópico: tal vez eso sea correcto em teoria, pero no sirve para la practica; Sobre um presunto derecho de mentir por filantropia. Madrid: Tecnos, 2006.

À Paz Perpétua. Porto Alegre: L\&PM Pocket, 2010.

KELSEN, Hans. La démocratie - sa nature, as valeur, cit., e General Theory of Law and State, 1945, trad. Portuguesa Teoria Geral do Direito e do Estado, Brasília, 1990.

LIMA, Newton de Oliveria. Kant e a fundamentação do direito subjetivo do cidadão à publicidade dos atos estatais. In: ETHICA, Rio de Janeiro, v. 18, n. 1, p. 129-147, 2011. 
O estado de direito em Kant e Kelsen. Belo Horizonte: Editora D’Plácido, 2017.

MARCACINI, Augusto Tavares Rosa; COSTA, Marcos da. Criptografia assimétrica, assinaturas digitais e a falácia da "neutralidade tecnológica" (Segredos protegidos). In: KAMINSKI, Omar (organizador). Internet legal: o direito na tecnologia da informação. Curitiba: Juruá, 2003.

MARTINS, Daniele Comin. Democracia participativa e participação popular. In: SANTOS, Rogerio Dultra dos. (org). Direito e política. Porto Alegre: Síntese, 2004.

MIRANDA, Jorge. Os princípios da democracia. In: LEITE, George Salomão; SARLET, Ingo Wolfgang. Constituição, política e cidadania. Porto Alegre: GIW Editora, 2013.

MOUGAYAR, William. Blockchain para negócios: promessa, prática e aplicação da nova tecnologia da internet. Traduzido por Vivian Sbravatti. Rio de Janeiro: Alta Books, 2017.

NAKAMOTO, Satoshi. Bitcoin: a peer-to-peer electronic cash system. 2008. Disponível em: <https://bitcoin.org/bitcoin.pdf>. Acesso em: 07 ago. 2019.

OLIVEIRA, Rafael Santos de; RODEGHERI, Letícia Bodanese. A utilização da internet e a construção da ciberdemocracia no Brasil. Portal e-Democracia. In: OLIVEIRA, Rafael Santos de; BUDÓ, Marília de Nardin (org.). Mídias e direitos da sociedade em rede. Ijuí: Ed. Unijuí, 2014.

ROUSSEAU, Jean-Jacques, 1712-1778. Do contrato social ou princípios do direito

político. Tradução Eduardo Brandão. Organização e introdução Maurice Cranston. São Paulo: Penguin Classics Companhia das Letras, 2011.

SOUZA, Bruno Ruiz de; SPAREMBERGER, Raquel Fabiana Lopes. Democracia e soberania como expressão do poder político: passado e presente. In: Teorias da democracia e direitos políticos. [Recurso eletrônico on-line] organização CONPEDI/UNISINOS. Coordenadores: Armando Albuquerque de Oliveira; José Filomeno de Moraes Filho; Karen Beltrame Becker Fritz. Florianópolis: CONPEDI, 2018, p. 73-92.

STIGLITZ, Joseph E. Sobre a liberdade, o direito de conhecer e o discurso público: o papal da transparência na vida pública. Traduzido por Mariana Pimentel Fischer Pacheco. In: SANTI, Eurico Marcos Diniz de et al. (coordenação). Transparência fiscal e desenvolvimento: homenagem ao professor Isaias Coelho. 1 ed. São Paulo: FISCOSoft Editora, 2013. 